\title{
The Mechanism of Wellbore Weakening in Worn Casing-Cement-Formation System
}

\author{
Zheng Shen, ${ }^{1}$ Frederick E. Beck, ${ }^{1}$ and Kegang Ling ${ }^{2}$ \\ ${ }^{1}$ Texas A\&M University, College Station, TX 77843, USA \\ ${ }^{2}$ University of North Dakota, Grand Forks, ND 58202, USA \\ Correspondence should be addressed to Zheng Shen; zheng.shen@weatherford.com
}

Received 25 February 2014; Accepted 3 June 2014; Published 24 June 2014

Academic Editor: Guillaume Galliero

Copyright (C) 2014 Zheng Shen et al. This is an open access article distributed under the Creative Commons Attribution License, which permits unrestricted use, distribution, and reproduction in any medium, provided the original work is properly cited.

\begin{abstract}
Maintaining casing integrity, in terms of downhole zonal isolations and well stability, is extremely important in oil/gas wells. Casing wear occurs not only in directional drilling, but also in vertical drilling with a slight deviation angle. In most hydrocarbon wells, deteriorated casing was reported from the onset of casing wear by the presence of friction force during the rotation of drillpipe. The friction force against the casing wall causes the reduction of casing strength. Furthermore, the rotation of drillpipe combined with corrosive drilling fluids could dramatically degrade the casing strength. We used a finite element analysis to focus on the stress evolution in worn casings. Comparison study between worn casing and perfect casing was conducted. Our study showed that the thermal load significantly increases the stress concentration of the worn casing in the wellbore. Finite element solutions indicated that the radial stress of the worn casing is not affected as much as the hoop stress. Along with the increased burst pressure or the elevated temperature, the unworn portion of the casing also suffers from severe compression stress. This work is important to broadening the understanding of well engineers through addressing the true stress profile of worn casing in cemented wellbore.
\end{abstract}

\section{Introduction}

Casing wear in the oil and gas industry is recorded on a world basis. Rotation of drillpipe during the drilling process creates significant contact forces that result in the reduction of casing wall thickness. Thickness reduction of the casing wall weakens the burst and collapse resistances of casing, where stress concentration at the worn location is expected. Casing wear will be accelerated in the presence of corrosive fluids.

Casing wear is a serious problem that is not limited to directional or extended wells. Because the contact pressure generated on the inner surface of the casing becomes much harder to control during the drill bit penetration into deep formations, worn casing is also found in vertical wells. The strength of the casing depends on the material and geometry of the casing; the calculation of the burst and collapse pressures of casing is given in the Appendix. All criteria indicate that the burst and collapse resistances strengthen with the increase of casing wall thickness.

Within the limited information about the stress profile of worn casings, casing wear is analyzed alone in models without including cement sheath and formation. The stress profiles of worn casing developed by using the existing isothermal models [1] are insufficient to provide the whole picture regarding how worn casing behaves in a downhole field condition. The drilling process becomes more complicated in deep formations where the temperature of wellbore fluids is significantly different in conventional wells. In event of the worn casing, maintaining the stability of the cased wellbore in high-pressure and high-temperature (HPHT) wells is challenging because of large potential variations of temperature and pressure. High temperature can bring significant pressure increase in the sealed annuli, which can lead to further failures of the casing string or the production liner [2].

Casing wear can be caused by different parts of drilling tools. Casing wear typically results from contact pressure of the casing and the tool joint. As shown in Figure 1, the tool joint represented by part 2 has a relatively small diameter compared to the casing represented by part 1 . The thickness of casing wall decreases because of the crescent-shaped wear by the tool joint indicted in the red area. After the reduction of casing wall thickness, stress caused by wellbore fluid pressure 


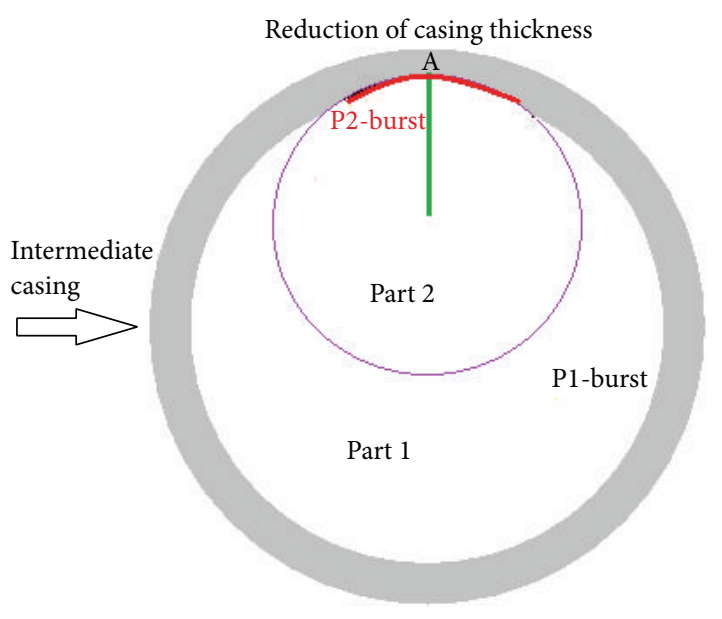

FIGURE 1: Crescent shape worn casing by the tool joint.

and formation in situ stresses is expected to be concentrated on the worn casing.

Thorough understanding of the true stress profile of worn casing leads to economic and safe casing design. Unfortunately, mechanical behaviors of casing from past studies were incomplete because of ignoring the formation and timedependent temperature effect. Researchers have investigated the stress profile of worn casing, focusing on the standalone casing $[3,4]$. Others found the relation of wear depth and contact force through experimental tests, with each wear depth recorded at a given contact force [5]. Researchers [6, 7] have also studied the effect of formation to casing. They concluded that the surrounding formation significantly increased the burst resistance of casing, but the work was applied to the isothermal downhole condition. None of the existing studies considered the thermal and mechanical behaviors of worn casing in a cemented well. The mechanism of wellbore weakening due to worn casing has not yet been sufficiently understood. The limitations of the existing models motivated us to determine true stress profile in and around worn casing in the cased hole.

This work aims to describe the stress concentration of casing after wear in a cemented well. The results showed that the formation in situ stresses and temperature largely impact the stress profile of the worn casing in the cemented wellbore. Casing uncemented with formation suffers from tension when the burst pressure is applied in the wellbore. Without considering the temperature effect in the worn casing, the stress concentration of the worn part is apparently underestimated. The traditional Lame equations for stress calculation in the wellbore are weakened by not including the temperature effect, cement sheath, and formation. The results also showed that the elevated temperature has expanded the worn casing and resulted in further compression in the worn casing. This work established the mechanical responses of worn casing through addressing the true stress profile of worn casing in cemented wellbore. The findings of the present work will be beneficial to well engineers.

\section{Previous Studies}

Uncemented casing suffers from serious tension when the burst pressure is applied on the inner wall of casing. For a perfect casing without wear in an isothermal condition, the radial stress and hoop stress can be evaluated using (1). The equations do not take into account the effects of cement sheath and formation:

$$
\begin{aligned}
& \sigma_{r}=\frac{p_{w} r_{w}^{2}}{r_{o}^{2}-r_{w}^{2}}\left(1-\frac{r_{o}^{2}}{r^{2}}\right)-\frac{p_{o} r_{o}^{2}}{r_{o}^{2}-r_{w}^{2}}\left(1-\frac{r_{w}^{2}}{r^{2}}\right), \\
& \sigma_{\theta}=\frac{p_{w} r_{w}^{2}}{r_{o}^{2}-r_{w}^{2}}\left(1+\frac{r_{o}^{2}}{r^{2}}\right)-\frac{p_{o} r_{o}^{2}}{r_{o}^{2}-r_{w}^{2}}\left(1+\frac{r_{w}^{2}}{r^{2}}\right) .
\end{aligned}
$$

The reduction of casing wall thickness mainly results from casing corrosion and casing wear. It is well known that drilling through sand formation zones causes serious erosion randomly along the casing pipe. Casing corrosion is categorized into several types. Decarburization is a hydrogencarbon attack of a component of any alloy under high temperature. Galvanic corrosion occurs when two dissimilar metals are in contact. This type of corrosion, most likely occurring in the surface casing, is normally seen as a result of the active macrocorrosion cells when the surface casing is not well cemented. Biological corrosion happens as a result of activities of living organisms. This happens in the environment of temperature ranging from $30^{\circ} \mathrm{F}$ to $180^{\circ} \mathrm{F}, \mathrm{pH}$ measurement of 0 to 11, and pressures up to 15,000 psi [8].

In drilling, the rotation of drillpipes could uniformly reduce the casing thickness from the inner surface of casing or create a crescent-shaped wear pattern. Researchers have focused on the wear volume of casing through laboratory measurements [9]. Casing wear can be caused by tool joints, drillpipe, and wireline. Casing wear by the drillpipes and wirelines is not as significant as that by the tool joints. Casing wear by tool joints is determined by the factors such as drill string rotation time and the speed, drilling mud properties, casing strength, and well dogleg severity.

Stress concentration around worn casing has been studied by some researchers. A casing wear model is largely weakened by not considering the temperature and formation. Researchers [1] focused on the rupture capacity of casing after wear. The analytical solution for the hoop stress at the surfaces of worn casing was constructed by dividing the entire worn casing into three superimposable shapes. To obtain the induced hoop stress of the worn casing, the superposition principle was adopted in a bipolar coordinate. Others argued that casing wear models can be simplified by assuming a slotted ring in the casing inner wall [3]. In their method, the resistance of the hoop stress is decreased because of the reduction of casing wall plus the extra burst pressure acting on the surfaces of the slotted ring. The stress under the worn surface was also investigated. The experimental work indicates that the area below the wear surface experiences unusual strain [10].

Researchers investigated the maximum wear groove depth resulting from the contact pressure applied to the inner wall of casing [4]. Various-size drill strings were used to find a relation for the groove depth of crescent-shaped casing wear 
as a function of time. The casing wear was tested in single, sharp, and blunt groove forms. Another study emphasized the alleviation and prevention of casing wear by using optimized well operations, such as dogleg severity control and sealant application in the worn sections [11].

\section{Numerical Modeling}

Casing wear causes significant reduction of the casing strength. Worn casing is under the risk of tangential collapse and radial cracking in the wellbore system. Force equilibrium can be expressed in terms of the normal force, shear force, and body force. The general relation of the forces in a cylindrical coordinate system is given in (2) [12]. Ideally, an analytical solution for the hoop stress in the worn casing is required. Typical Lame equations used in casing integrity analysis do not qualify for the effects of worn shape and formation. It is difficult to develop a reasonable and accurate analytical model investigating worn casing. Because the existing force balance equations are not suitable for addressing the effects of cement sheath, formation, and temperature in worn casing system, it is difficult to develop a reasonable and accurate analytical model investigating worn casing:

$$
\frac{\partial \sigma_{r}}{\partial r}+\frac{1}{r} \frac{\partial \tau_{r \theta}}{\partial_{\theta}}+\frac{\sigma_{r}-\sigma_{\theta}}{r}+\sigma f_{r}=0 .
$$

Alternatively, a finite element model can be used to overcome the limitations of the analytical models. Finite element analysis (FEA) is a computer-based numerical technique applied to many engineering problems. This method is popular in performing prejob designs for primary jobs or postmodified jobs for remedial actions. By using a finite element method, a structure, such as the casing-cementformation system, can be broken down into small elements composed of nodes in a global coordinate system. The deflections and stresses of all nodes must be calculated using computer programs because of the complexity of the global system. The computation time of solving for the finite element model depends on the number of total elements and computer performance.

The numerical simulator ANSYS was used. Numerical simulations were performed to analyze thermal and mechanical behaviors of worn casing in the cemented wellbore. In the present model, the worn casing was located in a vertical well and was perfectly cemented with the surrounding formation. Plane strain assumes that one direction of the investigated body is much larger than the other two directions. In our case, the vertical section of the wellbore is much larger than the radial direction. It is reasonable to construct a $2 \mathrm{D}$ numerical model based on the concept of plane strain, which leads to the following relations in (3). The strain of normal to the $x-y$ plane and the shear strains $\gamma_{x z}$ and $\gamma_{y z}$ are zero:

$$
\varepsilon_{z}=\gamma_{x z}=\gamma_{y z}=0 .
$$

Drilling fluids have significant effect on the stability of the wellbore system. Because of the geometry of the casing cement formation, the thermal energy exchange in the nearwellbore system reaches equilibrium in a short time. A past

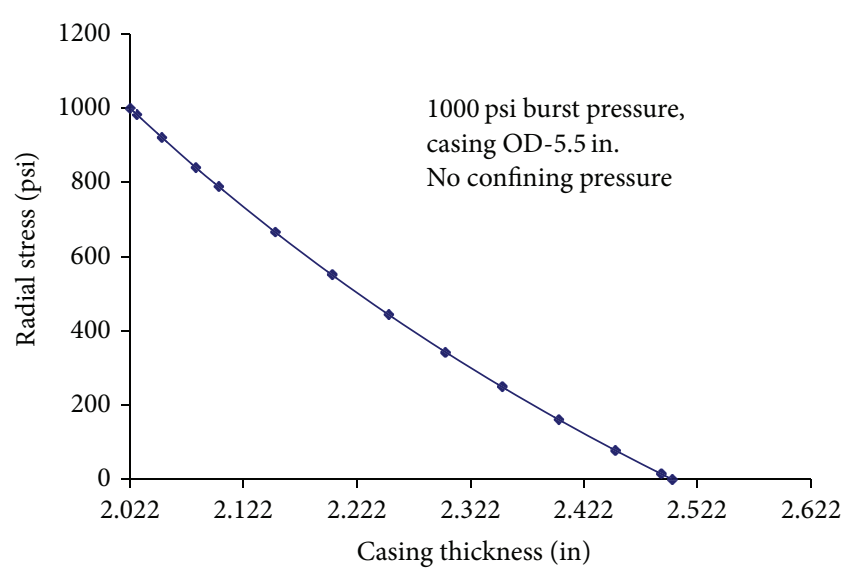

Figure 2: Casing radial stress in the radial direction.

study [13] has shown that wellbore fluids induce major stress change to the casing in the wellbore at the first hour. In this model, the minimum horizontal stress is equal to maximum stress. Fluids are pumping into the wellbore and circulating back to the surface through the wellbore annulus. The duration of the circulation is one hour. Wellbore fluid temperature is different from the formation temperature. The pressure and temperature at the boundaries are specified in the following:

$$
\begin{array}{ll}
r=r_{w}, & \sigma=p_{w}, \\
r=r_{o}, & \sigma=p_{o}, \\
r=r_{w}, & T=T_{w}, \\
r=r_{o}, & T=T_{o} .
\end{array}
$$

Accuracy of a finite element scheme measures the closeness between the analytical solution and the numerical solution. We first simplified the boundary conditions of the numerical model we used; thus the analytical solutions to the same problem can be found to verify the numerical results. Figures 2 and 3 show the radial stress and tangential stress of casing subject to the internal burst pressure of $1000 \mathrm{psi}$ while ignoring the formation effect. The numerical solution demonstrated a good match compared with the analytical result.

In this following study, the cased wellbore diameter of $6 \mathrm{in}$. is used, and the outer diameter of the formation is 10 times as large as the wellbore diameter. Cohesion force and friction angle of cement and rock are included in the simulations. The cohesion force is the force of attraction between the molecules of the same substance, and the friction angle measures the ability of rock or cement to resist the shear stresses. Other material properties of the worn casing cement formation used in the numerical model are listed in Tables 1 and 2.

A crescent shape of worn casing is assumed as shown in Figure 3. The reduction factor of worn casing is defined as the biggest reduction of casing thickness over the original casing thickness in (5). Field observations have shown that worn casing in many wells lost approximately $20 \%$ of the casing thickness [1]. The original casing thickness is $0.5 \mathrm{in}$. In the 
TABLE 1: Geometric and geomechanical properties.

\begin{tabular}{lcccccc}
\hline & ID (in.) & OD (in.) & Elastic modulus (psi) & Poisson ratio & Cohesion force (psi) & Friction angle $\left(^{\circ}\right)$ \\
\hline Casing & 6 & 7 & $2.80 E+07$ & 0.3 & Not applicable & Not applicable \\
Cement sheath & 7 & 9 & $3.00 E+06$ & 0.24 & $8.00 E+03$ & 30 \\
Formation & 9 & 60 & $6.00 E+06$ & 0.2 & $6.00 E+03$ & 30 \\
\hline
\end{tabular}

TABLE 2: Thermal properties.

\begin{tabular}{lcccc}
\hline & Density $\left(\mathrm{lb} / \mathrm{in}^{3}\right)$ & $\begin{array}{c}\text { Conductivity } \\
(\text { btu/in-hr-F })\end{array}$ & $\begin{array}{c}\text { Heat capacity } \\
(\text { Btu/lb-F })\end{array}$ & $\begin{array}{c}\text { Thermal expansion } \\
\left(\mathrm{F}^{-1}\right)\end{array}$ \\
\hline Casing & 0.253 & 0.6 & 0.12 & $1.8 E-05$ \\
Cement sheath & 0.065 & 0.05 & 0.5 & $1.2 E-05$ \\
Formation & 0.072 & 0.04 & 0.4 & $1.4 E-05$ \\
\hline
\end{tabular}

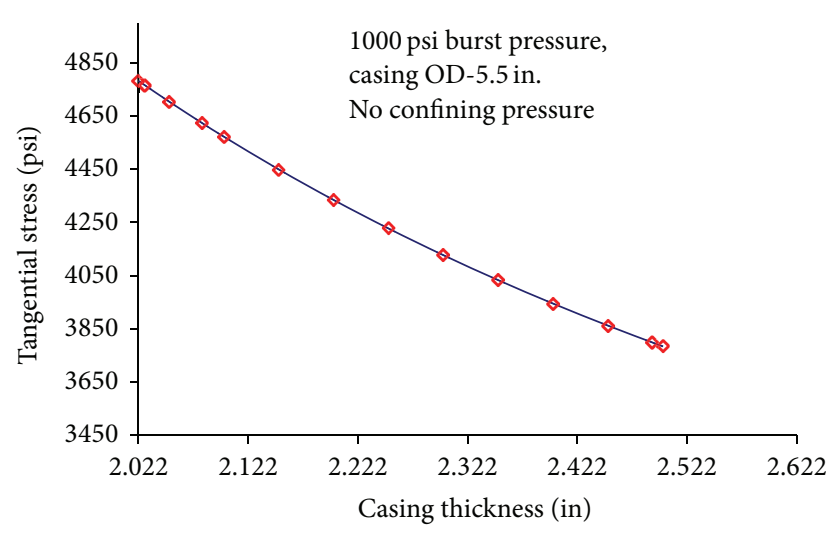

FIGURE 3: Casing tangential stress in the radial direction.

deepest worn point, $0.1 \mathrm{in}$. thickness of casing is lost after casing wear:

$$
\mathrm{RF}=\frac{h_{\text {initial }}-h_{\text {current }}}{h_{\text {initial }}} .
$$

Table 3 lists the fluid temperatures and pressures under different scenarios. To evaluate the stress concentration in the worn casing, six base models were built with either different temperatures or wellbore pressures in the model. Case 1 simulates the perfect casing-cement-formation system without casing wear. Case 2 through 6 are used for the worn casing-cement-formation system in different wellbore fluid pressure and temperature. The results analysis is presented in the next section.

\section{Results}

The results presented are near-wellbore mechanical behaviors when the wellbore fluids flow in the worn casing-cementformation system. Although stresses and displacements at any location can be found using this model, our discussions focus on the casing-cement case. Contour figures are used to show the stress distributions in different downhole conditions. In the model, a negative sign represents the compression and a positive sign is for tension.

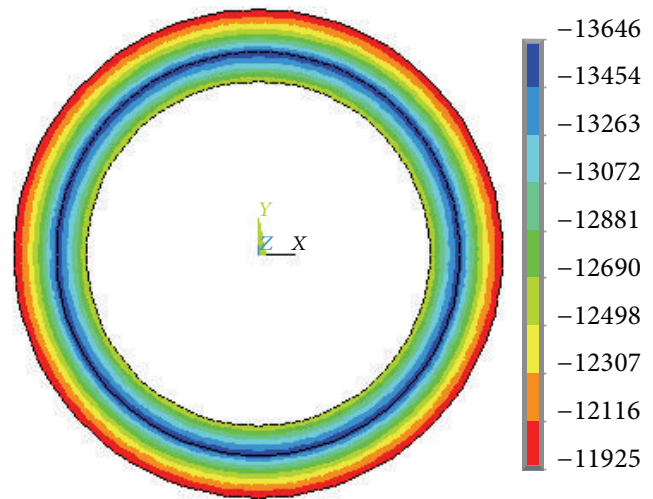

Perfect wellbore

FIgURE 4: Radial stress inside the perfect casing cement for Case 1.

Case 1. The aim of this case is to validate this model. The results presented in Figures 4 and 5 are consistent with the existing solutions. In previous studies, different researchers predict the maximum radial stress at the casing-cement interface in a perfect casing-cement system [6]. In Case 1, the perfect casing without thermal effects and wear is analyzed. The figures reveal the contour profiles of radial stress and hoop stress in the casing-cement part. The maximum radial stress reaches approximately 13,600 psi, which is uniformly distributed at the casing-cement interface. The inner wall of the casing suffers from the highest hoop stress.

Case 2. The reduction of casing thickness decreases the casing strength. No heat transfer occurs in Case 2 because the temperatures of the fluid and rock are identical. Although the casing is worn, the maximum radial stress still occurs at the interface of casing and cement. There is little difference between the radial stresses in the worn part and those in the unworn part, as shown in Figure 6.

The tension failure of worn casing will be overestimated without considering the confining effect of cement and rock. A previous study shows that the wellbore burst pressure causes severe tangential tension at the worn casing [3]. 
TABLE 3: Fluid temperature and burst pressure for six cases.

\begin{tabular}{|c|c|c|c|c|c|c|}
\hline & $\begin{array}{l}\text { Wellbore fluid } \\
\text { temperature }\left({ }^{\circ} \mathrm{F}\right)\end{array}$ & $\begin{array}{c}\text { Formation } \\
\text { temperature }\left({ }^{\circ} \mathrm{F}\right)\end{array}$ & $\begin{array}{l}\text { Initial temperature } \\
\qquad\left({ }^{\circ} \mathrm{F}\right)\end{array}$ & Burst pressure (psi) & $\begin{array}{l}\text { Rock in situ stress } \\
\text { (psi) }\end{array}$ & Casing \\
\hline Case 1 & 350 & 350 & 350 & 12,500 & 11,000 & Perfect \\
\hline Case 2 & 350 & 350 & 350 & 12,500 & 11,000 & Worn \\
\hline Case 3 & 450 & 350 & 350 & 12,500 & 11,000 & Worn \\
\hline Case 4 & 450 & 350 & 350 & 13,500 & 11,000 & Worn \\
\hline Case 5 & 450 & 350 & 350 & 14,500 & 11,000 & Worn \\
\hline Case 6 & 450 & 350 & 350 & 13,500 & 0 & Worn \\
\hline
\end{tabular}

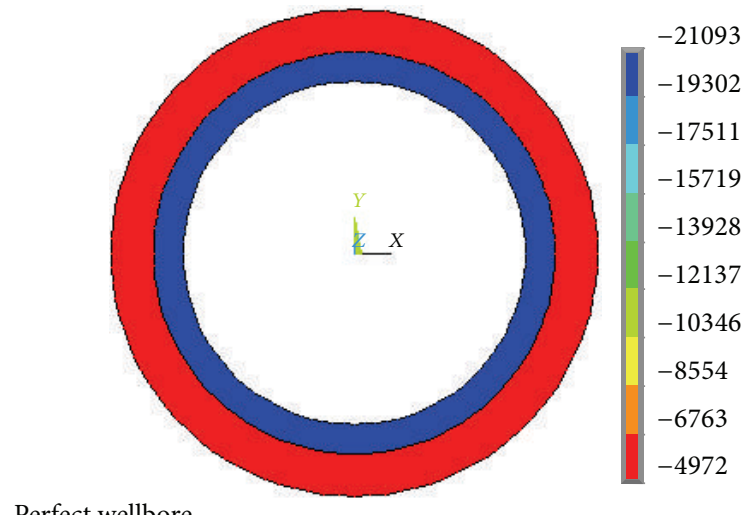

Perfect wellbore

FIgURE 5: Hoop stress inside the perfect casing cement for Case 1.

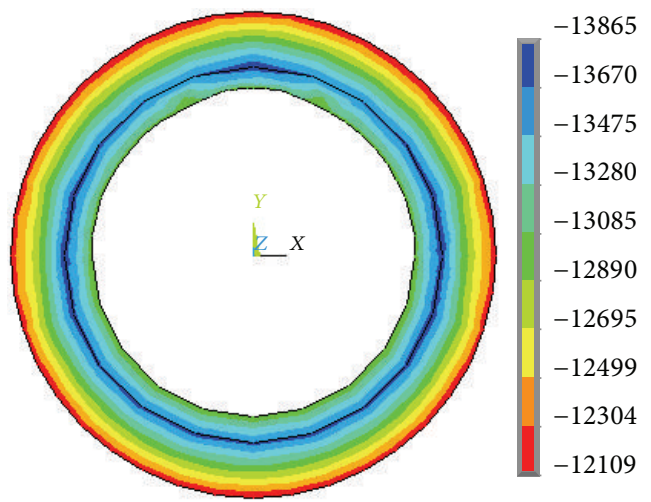

No temperature effect

FIGURE 6: Radial stress inside the worn casing cement for Case 2.

This occurs because the burst pressure in the uncemented wellbore produces the tension only when the casing stands alone. Figure 7 shows that the large compression hoop stress occurring around the worn area likely causes the yield of worn casing.

Case 3. The fluid temperature is $450^{\circ} \mathrm{F}$, which is much higher than the rock temperature of $350^{\circ} \mathrm{F}$. Thermal stress acts on the casing-cement part until the heat transfer reaches equilibrium. Compared with the maximum radial stress of

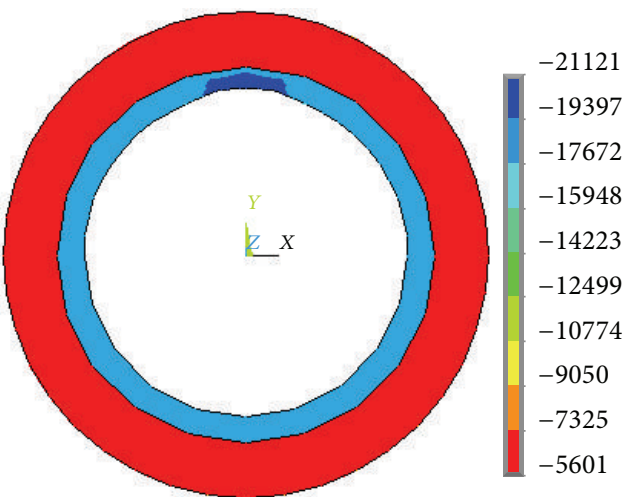

No temperature effect

FIGURE 7: Hoop stress inside the worn casing cement for Case 2.

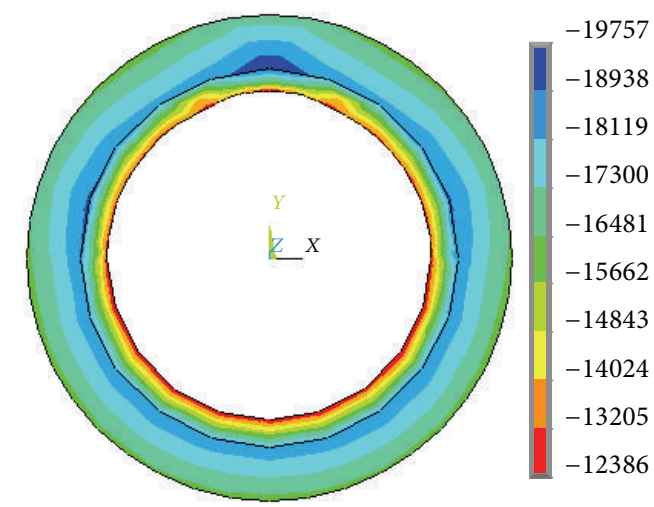

1h-fem

FIGURE 8: Radial stress inside the worn casing cement for Case 3.

13,866 psi in Case 2, maximum radial stress in the casingcement part is increased by one-third because of the thermal stress (Figure 8).

The casing is still constrained by the cement and formation, but the elevated temperature in the casing-cementformation system resulting from the wellbore fluids tends to cause expansion of the worn casing. The results shown in Figures 8 and 9 indicate that the consequence of the casing expansion is to produce further compression on the casingcement part. The maximum hoop stress of 73,791 psi in Case 3 is close to three times larger than the 21,121 psi in Case 2. 


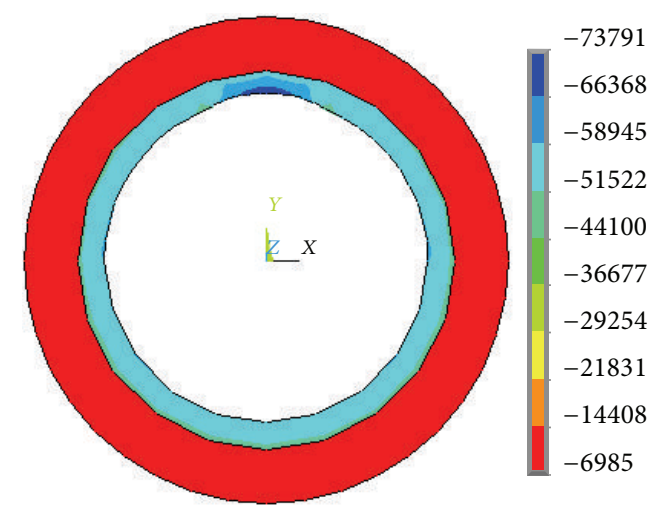

1h-fem

FIGURE 9: Hoop stress inside the worn casing cement for Case 3.

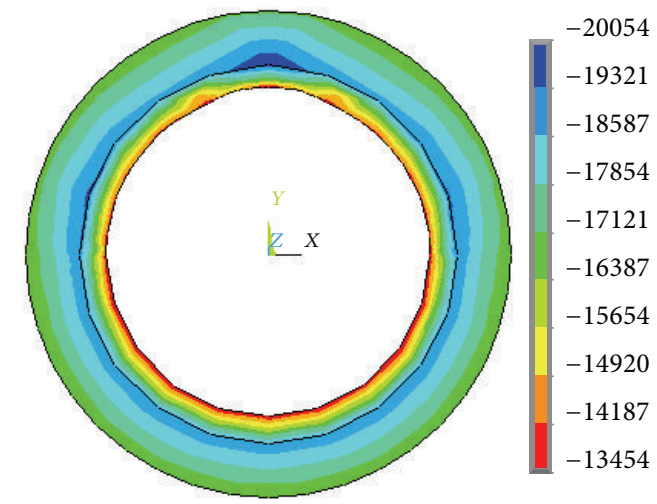

lh-fem

FIgURE 10: Radial stress inside the worn casing cement for Case 4.

It is concluded that the increase of hoop stress is much more than the increase of radial stress in the worn casing cement due to the thermal effect. Several types of casings will fail under this circumstance. The minimum yield strength of casing strings such as J55 and K55 is 55,000 psi. The high temperature difference in the wellbore could put the worn casing-cement-formation system under high risk of failure.

Case 4. The temperature profile is unchanged. The burst pressure of 13,500 psi is used. The compression radial stress in the worn casing cement is slightly larger than that in Case 3, as shown in Figure 10. This indicates that the larger the wellbore burst pressure, the greater the induced casing radial stress resulting from the higher fluid pressure acting on the inner wall of the wellbore.

It is interesting to note that the hoop stress inside the worn casing cement caused by the burst pressure of $13,500 \mathrm{psi}$ is lower than that by the burst pressure of $12,500 \mathrm{psi}$, as shown in Figure 11. This hoop stress is decreased from $73,791 \mathrm{psi}$ to $68,671 \mathrm{psi}$. The thermal expansion of casing in the constrained environment due to the cement and formation causes extremely large compression tangential stress, whereas the increased burst pressure tends to expand the worn casing in the opposite direction. It is concluded that a higher burst

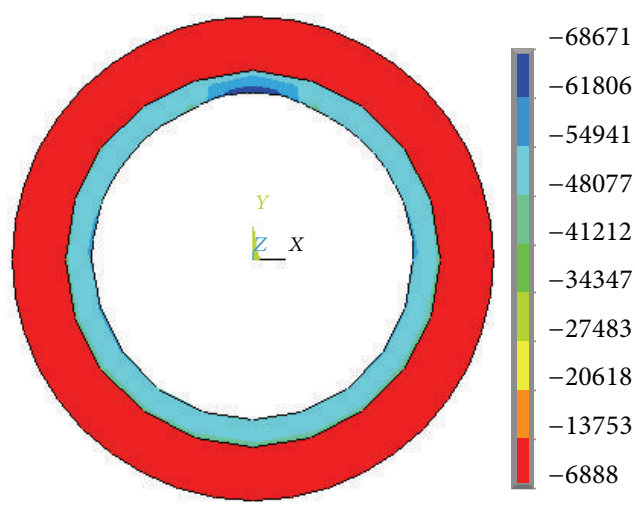

1h-fem

FIGURE 11: Hoop stress inside the worn casing cement for Case 4.

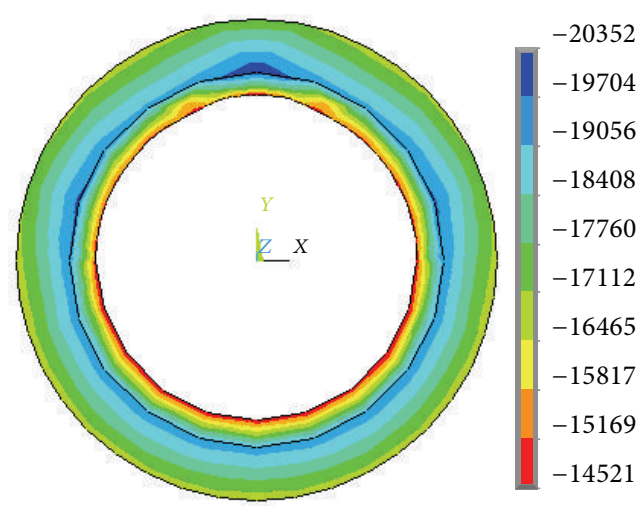

1h-fem

FIGURE 12: Radial stress inside the worn casing cement for Case 5.

pressure in the wellbore could reduce the maximum hoop stress in the worn casing-cement part.

Case 5. Figures 12 and 13 reveal the radial stress and hoop stress profile in the worn casing-cement system. The temperature profile in Case 5 is identical with that used in Cases 2 and 3 . The burst pressure increases to 14,500 psi. The results show that the radial stress in the system slightly increases with a bigger burst pressure. As expected, the maximum hoop stress occurs on the worn part, and it decreases by 5,000 psi along with the increase of burst pressure.

Cases 2 to 5 present stress profiles of the worn casing under different burst pressures. The stress concentration on the worn part in the casing-cement-formation is predicted in all cases. The risk of tangential compression failure in the worn casing decreases along with the increase of burst pressure.

Case 6. Figures 14 and 15 show the radial stress and hoop stress of the worn casing cement, respectively. The results reveal that the formation is important to prevent tension failure on the worn casing. To better illustrate mechanical behaviors of the worn casing caused by the cement and formation, zero formation in situ stress is used in this case. 


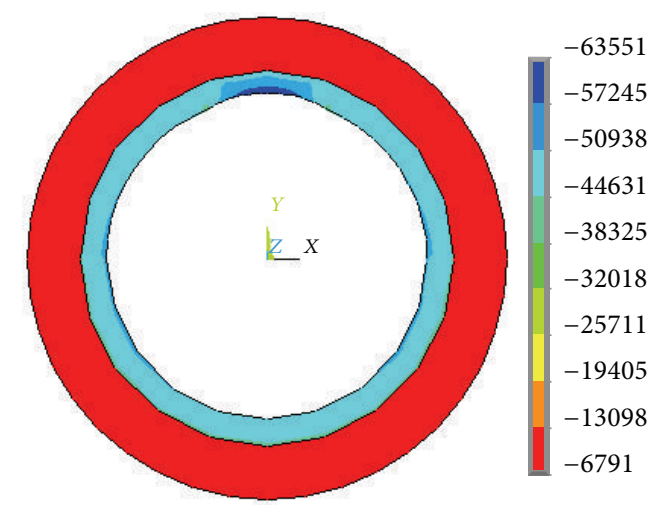

1h-fem

Figure 13: Hoop stress inside the worn casing cement for Case 5.

The maximum radial stress occurs on the inner wall of the worn casing, which differs from Cases 1 to 4 . The maximum hoop stress, as shown in Figure 15, occurs on the worn part. The worn casing suffers from extreme tension without the formation in situ stress.

\section{Conclusions}

The present numerical model has addressed the complete wellbore system consisting of wellbore fluid, casing, cement, and formation. Two principal stresses are analyzed in different downhole conditions. A worn casing-cement-formation model is built using finite element analysis. Ignoring the effect of temperature, the induced stresses in the worn casingcement-formation system were slightly higher than that in a perfect casing-cement-formation system. In this study, casing expansion due to the temperature difference between wellbore and formation produces severe compression on the worn casing-cement part. The results show that the induced stress could exceed the minimum yield strength of casing strings such as J55 and K55.

Although the casing thickness is partially reduced after wear, worn casing in the downhole system suffers from apparent stress concentration. It is concluded that the increase of the hoop stress is much more than the increase of radial stress in the worn casing cement due to the thermal effect. The burst pressure tends to cause the tension of worn casing. The effects of formation and temperature dominate the stress distribution of the worn casing. It is important to note that high wellbore burst pressures facilitate lowering the compression tangential failure in the worn casing-cement part in the cemented wellbore.

\section{Appendix}

Burst Pressure. The burst criteria for casing design are used to guarantee the integrity of casing burst resistance. Besides the API standard shown in (A.1), other researchers propose the initial yield burst standard, the full yield burst standard, and the rupture burst standard [3]. The initial stress criteria in (A.2) emphasize the casing initial yield at the inner wall of

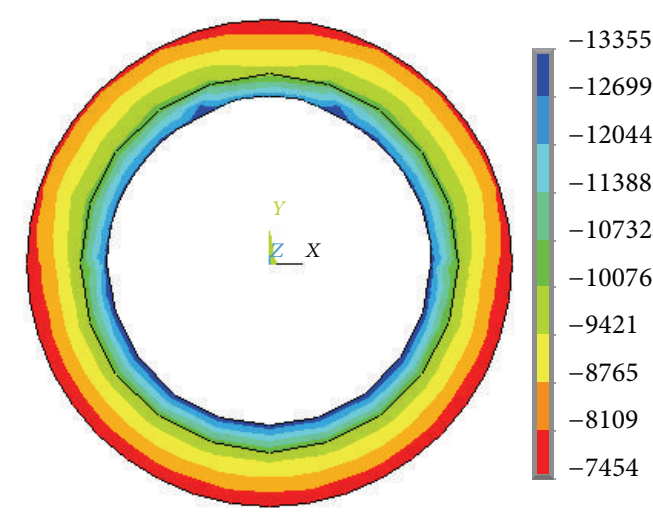

1h-fem

Figure 14: Radial stress inside the worn casing cement for Case 6.

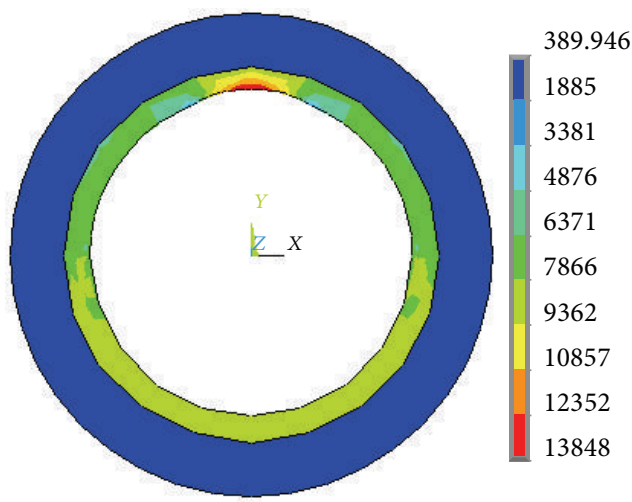

1h-fem

FIGURE 15: Hoop stress inside the worn casing cement for Case 6.

casing. Equation (A.3) describes the casing yield across the entire casing wall under the full yield criteria. The rupture criterion is based on casing ductile and tensile failure, as shown in (A.4). Consider the following:

$$
\begin{gathered}
p_{\mathrm{API}}=\frac{1.75 Y_{m} t}{D}, \\
p_{\mathrm{IY}}=\frac{1.75 Y_{m}}{\sqrt{3}} \frac{2 t}{D}\left(1-\frac{t}{D}\right), \\
p_{\mathrm{FY}}=\frac{1.75 Y_{m}}{\sqrt{3}} \frac{2 t}{D}\left(1+\frac{t}{D}\right), \\
p_{\mathrm{DR}}=\frac{1.75 Y_{m} t}{D-t} .
\end{gathered}
$$

Collapse Pressure. API presents four types of collapse criteria for casing collapse design, which are indicated in (A.5) to (A.8). They comprise yield, plastic, transition, and elastic criteria. The proper selection of each standard depends on the casing wall thickness and diameter. To overcome the limitation of the elastic-plastic boundary under the API 
yield criteria, Tamano [14] proposes a general yield pressure equation, shown in (A.9). Consider the following:

$$
\begin{gathered}
p_{Y}=2 Y_{m} \frac{D / t-1}{(D / t)^{2}}, \\
p_{p}=Y_{m}\left(\frac{F_{1}}{d / t}-F_{2}\right)-F_{3}, \\
p_{E}=2 \frac{E}{1-v^{2}} \frac{1}{D / t(D / t-1)^{2}}, \\
p_{T}=Y_{m}\left(\frac{F_{4}}{d / t}-F_{5}\right), \\
p_{\mathrm{Ta}}=2 Y_{m}\left(\frac{D / t-1}{(D / t)^{2}}\right)\left(1+\frac{1.47}{D / t-1}\right) .
\end{gathered}
$$

\section{Nomenclature}

$\begin{array}{ll}\sigma_{r}: & \text { Radial stress } \\ \sigma_{\theta}: & \text { Hoop stress } \\ \sigma_{z}: & \text { Axial stress } \\ \varepsilon_{i=r, \theta, z}: & \text { Strain } \\ r_{w}: & \text { Inner radius of casing } \\ r_{o}: & \text { Outer radius of casing } \\ r_{2}: & \text { The outer radius of tool joint } \\ p_{w}: & \text { Burst pressure } \\ p_{o}: & \text { Collapse pressure } \\ Y_{m}: & \text { Yield stress of material } \\ t: & \text { Casing thickness } \\ D: & \text { Casing outer diameter } \\ F_{i}(i=1 \text { to } 5): \text { American Petroleum Institute (API) } & \text { coefficient for casing collapse criteria } \\ f_{r}: & \text { Body force } \\ E: & \text { Young's modulus } \\ v: & \text { Poisson's ratio. }\end{array}$

\section{Conflict of Interests}

The authors declare that there is no conflict of interests regarding the publication of this paper.

\section{References}

[1] J. S. Song, J. Bowen, and F. Klementich, "Internal pressure capacity of crescent-shaped wear casing," in Proceedings of the IADC/SPE Drilling Conference, pp. 547-553, New Orleans, La, USA, February 1992.

[2] P. Oudeman and M. Kerem, "Transient behavior of annular pressure build-up in HP/HT wells," in Proceedings of the 11th ADIPEC: Abu Dhabi International Petroleum Exhibition and Conference, pp. 665-674, Abu Dhabi, UAE, October 2004.

[3] J. Wu and M. G. Zhang, "Casing burst strength after casing wear," in Proceedings of the SPE Production and Operations Symposium 2005, pp. 517-526, Oklahoma City, Okla, USA, April 2005.

[4] R. W. Hall Jr. and K. P. Malloy Sr., "Contact pressure threshold: an important new aspect of casing wear," in SPE Production and Operations Symposium 2005: Anticipate the Future, Build on the
Present, Celebrate the Past, pp. 499-505, Society of Petroleum Engineers, Oklahoma City, Okla, USA, April 2005.

[5] D. Gao, L. Sun, and J. Lian, "Prediction of casing wear in extended-reach drilling," Petroleum Science, vol. 7, no. 4, pp. 494-501, 2010.

[6] W. W. Fleckenstein, A. W. Eustes III, and M. G. Miller, "Burstinduced stresses in cemented wellbores," SPE Drilling and Completion, vol. 16, no. 2, pp. 74-82, 2001.

[7] W. J. Rodriguez, W. W. Fleckenstein, and A. W. Eustes, "Simulation of collapse loads on cemented casing using finite element analysis," in Proceedings of the SPE Annual Technical Conference and Exhibition, pp. 5239-5247, Denver, Colo, USA, October 2003.

[8] S. Talabani, B. Atlas, M. B. Al-Khatiri, and M. R. Islam, "An alternate approach to downhole corrosion mitigation," Journal of Petroleum Science and Engineering, vol. 26, no. 1-4, pp. 41-48, 2000.

[9] W. B. Bradley and J. E. Fontenot, "The prediction and control of casing wear (includes associated papers 6398 and 6399)," SPE Journal of Petroleum Technology, vol. 27, no. 2, pp. 233-245, 1975.

[10] W. M. Rainforth, "Microstructural evolution at the worn surface: a comparison of metals and ceramics," Wear, vol. 245, no. 1-2, pp. 162-177, 2000.

[11] B. Calhoun, S. Langdon, J. Wu, P. Hogan, and K. Rutledge, "Casing wear prediction and management in deepwater wells," in Proceedings of the SPE Deepwater Drilling and Completions Conference 2010, pp. 232-241, Society of Petroleum Engineers, Galveston, Tex, USA, October 2010.

[12] E. Fjar, R. M. Holt, A. M. Raaen, R. Risnes, and P. Horsrud, Petroleum Related Rock Mechanics, Elsevier, Oxford, UK, 2004.

[13] Z. Shen and F. E. Beck, "Three-dimensional modeling of casing and cement sheath behavior in layered, nonhomogeneous formations," in Proceedings of the IADC/SPE Asia Pacific Drilling Technology Conference 2012, pp. 949-958, Society of Petroleum Engineers, July 2012.

[14] T. Tamano, "A new empirical formula for collapse resistance of commercial casing," in ASME Transactions of Energy Resources Technology, 2005. 

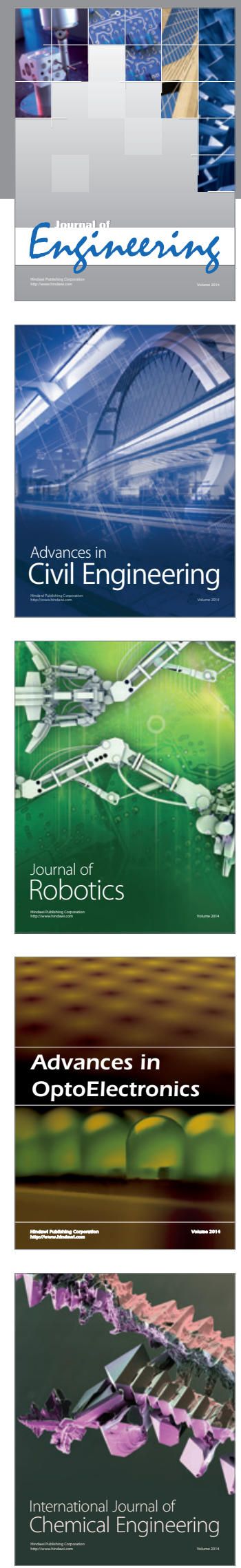

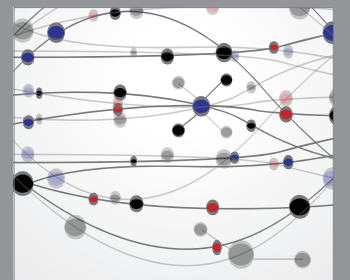

The Scientific World Journal
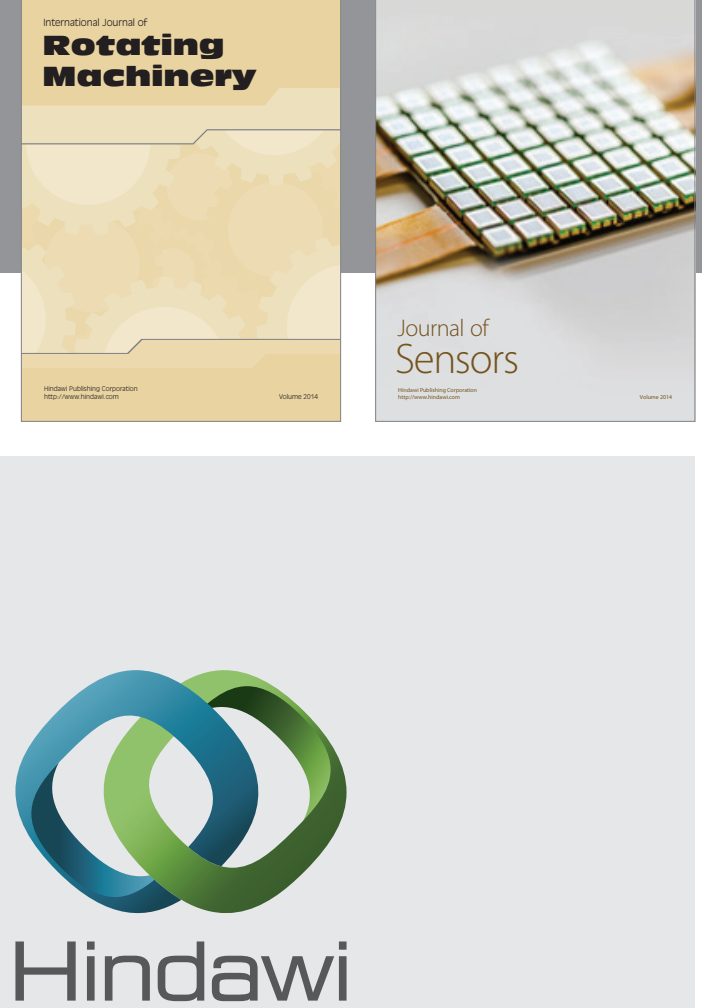

Submit your manuscripts at http://www.hindawi.com
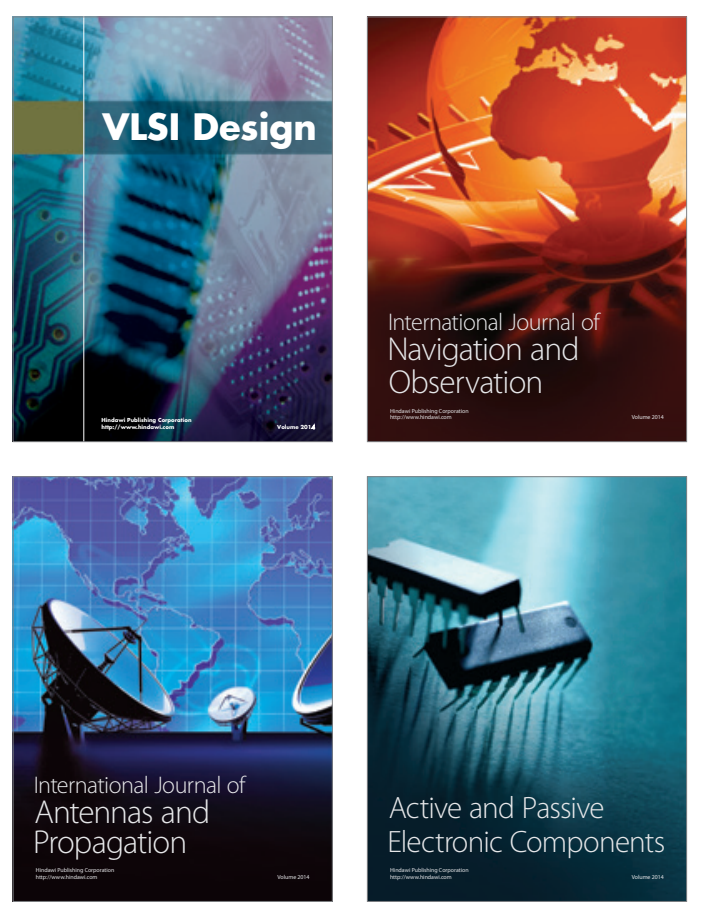
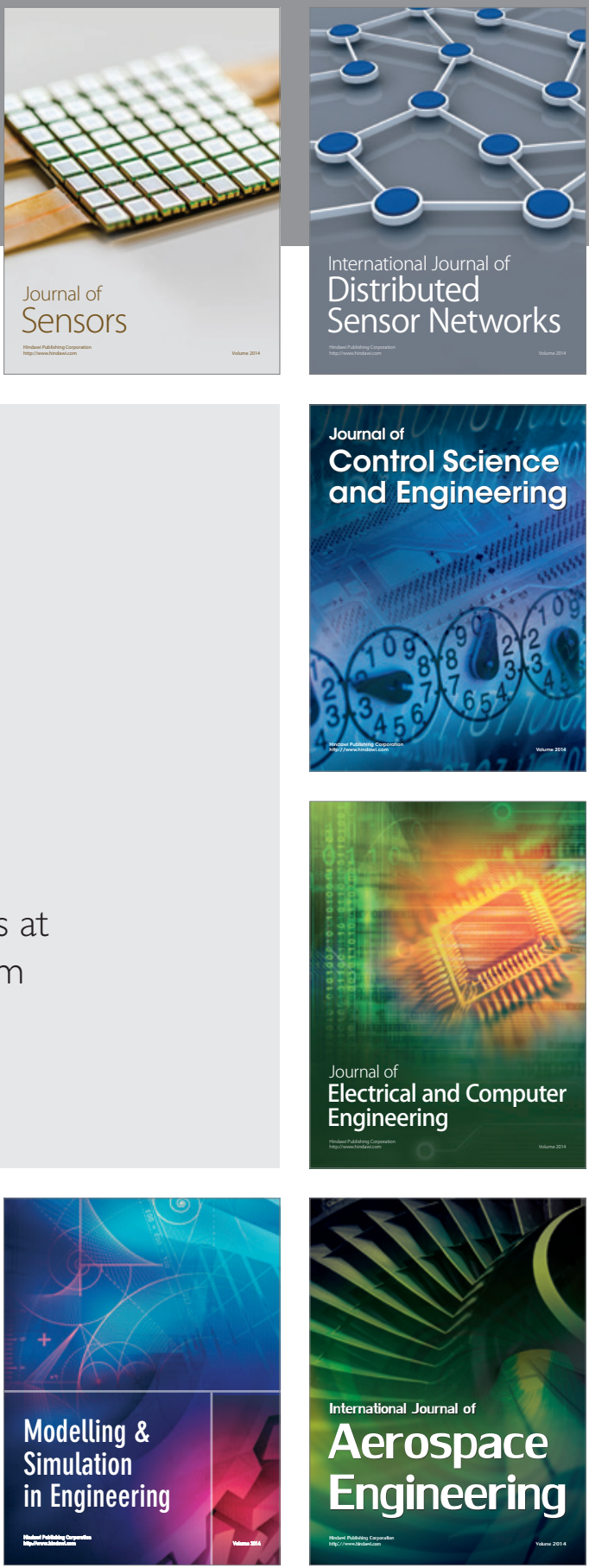

Journal of

Control Science

and Engineering
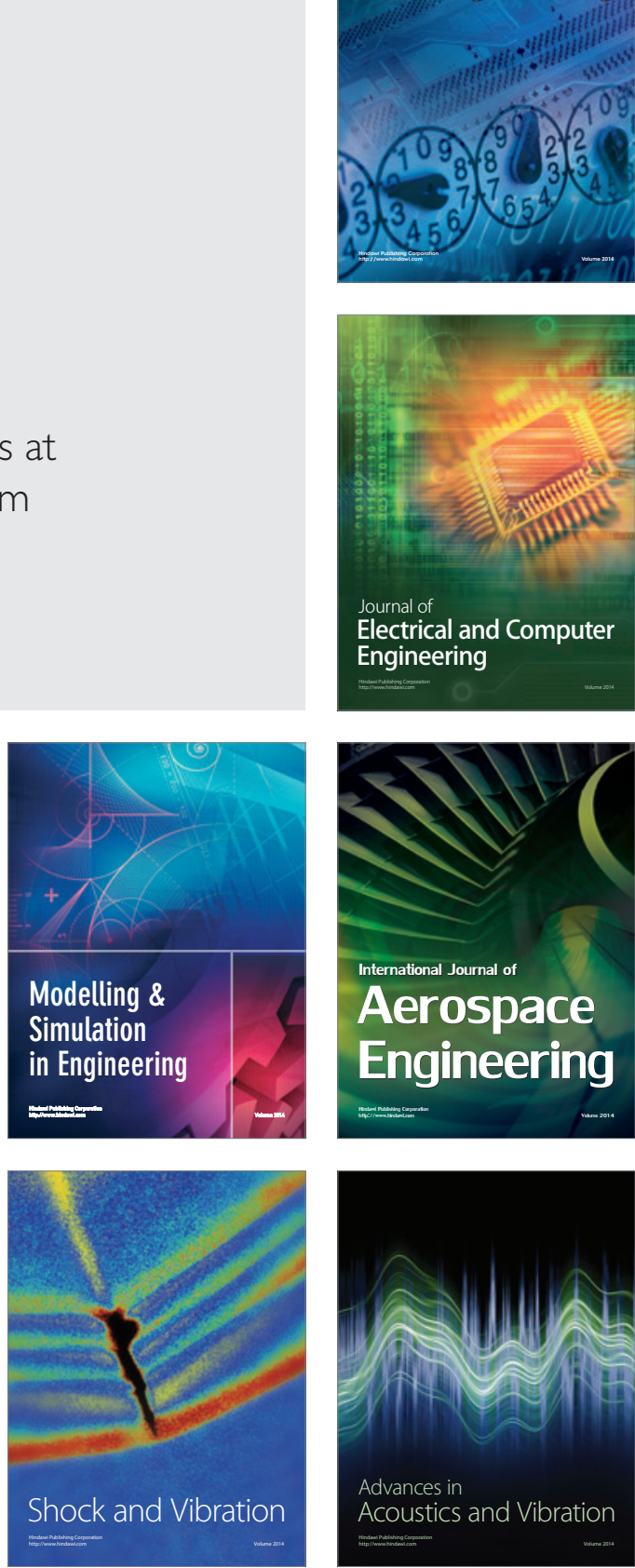